\title{
THE EQUIVALENCE OF MANN ITERATION AND ISHIKAWA ITERATION FOR NON-LIPSCHITZIAN OPERATORS
}

\section{B. E. RHOADES and ŞTEFAN M. ŞOLTUZ}

Received 25 November 2002

We show that the convergence of Mann iteration is equivalent to the convergence of Ishikawa iteration for various classes of non-Lipschitzian operators.

2000 Mathematics Subject Classification: 47H10.

1. Introduction. Let $X$ be a real Banach space, $B$ a nonempty, convex subset of $X$, and $T: B \rightarrow B$ an operator. Let $u_{1}, x_{1} \in B$. The following iteration is known as Mann iteration (see [6]):

$$
u_{n+1}=\left(1-\alpha_{n}\right) u_{n}+\alpha_{n} T u_{n} .
$$

The sequence $\left(\alpha_{n}\right)_{n} \subset(0,1)$ is convergent such that

$$
\lim _{n \rightarrow \infty} \alpha_{n}=0, \quad \sum_{n=1}^{\infty} \alpha_{n}=\infty .
$$

Ishikawa iteration is given by (see [5])

$$
\begin{aligned}
x_{n+1} & =\left(1-\alpha_{n}\right) x_{n}+\alpha_{n} T y_{n}, \\
y_{n} & =\left(1-\beta_{n}\right) x_{n}+\beta_{n} T x_{n}, \quad n=1,2, \ldots
\end{aligned}
$$

The sequences $\left(\alpha_{n}\right)_{n},\left(\beta_{n}\right)_{n} \subset(0,1)$ are convergent such that

$$
\lim _{n \rightarrow \infty} \alpha_{n}=0, \quad \lim _{n \rightarrow \infty} \beta_{n}=0, \quad \sum_{n=1}^{\infty} \alpha_{n}=\infty .
$$

Moreover, the sequence $\left(\alpha_{n}\right)_{n}$ from (1.3) is the same as in (1.1).

The map $J: X \rightarrow 2^{X^{*}}$ given by $J x:=\left\{f \in X^{*}:\langle x, f\rangle=\|x\|^{2},\|f\|=\|x\|\right\}$, for all $x \in X$, is called the normalized duality mapping. The Hahn-Banach theorem assures that $J x \neq \varnothing$, for all $x \in X$. It is easy to see that we have $\langle j(x), y\rangle \leq$ $\|x\|\|y\|$, for all $x, y \in X$ and for all $j(x) \in J(x)$.

DEFINITION 1.1. Let $X$ be a real Banach space and let $B$ be a nonempty subset. A map $T: B \rightarrow B$ is called strongly pseudocontractive if there exist $k \in(0,1)$ and a $j(x-y) \in J(x-y)$ such that

$$
\langle T x-T y, j(x-y)\rangle \leq k\|x-y\|^{2}, \quad \forall x, y \in B .
$$


A map $S: D(S) \rightarrow X$ is called strongly accretive if there exist $k \in(0,1)$ and a $j(x-y) \in J(x-y)$ such that

$$
\langle S x-S y, j(x-y)\rangle \geq k\|x-y\|^{2}, \quad \forall x, y \in D(S) .
$$

In (1.5), when $k=1, T$ is called pseudocontractive. In (1.6), when $k=0, S$ is called accretive. We denote by $I$ the identity map.

REMARK 1.2. (i) The operator $T$ is (strongly) pseudocontractive map if and only if $(I-T)$ is (strongly) accretive.

(ii) If $S$ is accretive map, then $T=f-S$ is strongly pseudocontractive map.

Remark 1.2(i) is obvious from (1.5) and (1.6). For Remark 1.2(ii), supposing that $x, y \in B$ and $j(x-y) \in J(x-y)$, one obtains

$$
\begin{aligned}
\langle S x-S y, j(x-y)\rangle \geq 0 & \Longleftrightarrow\langle(f-T) x-(f-T) y, j(x-y)\rangle \geq 0 \\
& \Longleftrightarrow\langle T x-T y, j(x-y)\rangle \leq 0 \leq k\|x-y\|^{2},
\end{aligned}
$$

for all $k \in(0,1)$.

In [10], it was shown that the Mann and Ishikawa iterations are equivalent for various classes of Lipschitzian operators. We prove here the equivalence for non-Lipschitzian operators. For this purpose, we need several lemmas.

LEMMA 1.3 [11]. Let $\left(a_{n}\right)_{n}$ be a nonnegative sequence which satisfies the following inequality:

$$
a_{n+1} \leq\left(1-\lambda_{n}\right) a_{n}+\sigma_{n},
$$

where $\lambda_{n} \in(0,1)$, for all $n \in \mathbb{N}, \sum_{n=1}^{\infty} \lambda_{n}=\infty$, and $\sigma_{n}=o\left(\lambda_{n}\right)$. Then $\lim _{n \rightarrow \infty} a_{n}=0$.

It is known that $J(x)=\partial \phi(x)$, where $\phi(x)=(1 / 2)\|x\|^{2}$ and $\partial \phi(x)$ denotes the subdifferential of $\phi(x)$ at $x$, so the following inequality is satisfied, see also [1, Lemma 2.1] or [9, Lemma 1].

LEMMA 1.4 [1, 9]. If $X$ is a real Banach space, then the following relation is true:

$$
\|x+y\|^{2} \leq\|x\|^{2}+2\langle y, j(x+y)\rangle, \quad \forall x, y \in X, \forall j(x+y) \in J(x+y) .
$$

2. Main result. We are now able to prove the following result.

THEOREM 2.1. Let $X$ be a real Banach space with a uniformly convex dual and $B$ a nonempty, closed, convex, and bounded subset of $X$. Let $T: B \rightarrow B$ be a continuous and strongly pseudocontractive operator. Then for $u_{1}=x_{1} \in B$, the following assertions are equivalent:

(a) Mann iteration (1.1) converges to the fixed point of $T$;

(b) Ishikawa iteration (1.3) converges to the fixed point of $T$. 
Proof. Deimling [3, Corollary 1] assures the existence of a fixed point. The uniqueness of the fixed point comes from (1.5). Because $X^{*}$ is uniformly convex, the duality map is single valued (see, e.g., [4]). Using (1.1), (1.3), and Lemma 1.4, we get

$$
\begin{aligned}
\left\|x_{n+1}-u_{n+1}\right\|^{2}= & \left\|\left(1-\alpha_{n}\right)\left(x_{n}-u_{n}\right)+\alpha_{n}\left(T y_{n}-T u_{n}\right)\right\|^{2} \\
\leq & \left(1-\alpha_{n}\right)^{2}\left\|x_{n}-u_{n}\right\|^{2}+2 \alpha_{n}\left\langle T y_{n}-T u_{n}, J\left(x_{n+1}-u_{n+1}\right)\right\rangle \\
= & \left(1-\alpha_{n}\right)^{2}\left\|x_{n}-u_{n}\right\|^{2} \\
& +2 \alpha_{n}\left\langle T y_{n}-T u_{n}, J\left(x_{n+1}-u_{n+1}\right)-J\left(y_{n}-u_{n}\right)\right\rangle \\
& +2 \alpha_{n}\left\langle T y_{n}-T u_{n}, J\left(y_{n}-u_{n}\right)\right\rangle \\
\leq & \left(1-\alpha_{n}\right)^{2}\left\|x_{n}-u_{n}\right\|^{2}+2 \alpha_{n} k\left\|y_{n}-u_{n}\right\|^{2} \\
& +2 \alpha_{n}\left\langle T y_{n}-T u_{n}, J\left(x_{n+1}-u_{n+1}\right)-J\left(y_{n}-u_{n}\right)\right\rangle \\
\leq & \left(1-\alpha_{n}\right)^{2}\left\|x_{n}-u_{n}\right\|^{2}+2 \alpha_{n} k\left\|y_{n}-u_{n}\right\|^{2} \\
& +2 \alpha_{n}\left\|T y_{n}-T u_{n}\right\|\left\|J\left(x_{n+1}-u_{n+1}\right)-J\left(y_{n}-u_{n}\right)\right\| \\
\leq & \left(1-\alpha_{n}\right)^{2}\left\|x_{n}-u_{n}\right\|^{2}+2 \alpha_{n} k\left\|y_{n}-u_{n}\right\|^{2} \\
& +2 \alpha_{n} M_{1}\left\|J\left(x_{n+1}-u_{n+1}\right)-J\left(y_{n}-u_{n}\right)\right\|,
\end{aligned}
$$

for some positive constant $M_{1}$. Observe that $\left(\left\|T y_{n}-T u_{n}\right\|\right)_{n}$ is bounded. We now prove that

$$
J\left(x_{n+1}-u_{n+1}\right)-J\left(y_{n}-u_{n}\right) \longrightarrow 0 \quad(n \rightarrow \infty) .
$$

Deimling [4, Proposition 12.3, page 115] assures that when $X^{*}$ is uniformly convex, $J$ is uniformly continuous on every bounded set of $X$. To prove (2.2), it is sufficient to see that

$$
\begin{aligned}
& \left\|\left(x_{n+1}-u_{n+1}\right)-\left(y_{n}-u_{n}\right)\right\| \\
& \quad=\left\|\left(x_{n+1}-y_{n}\right)-\left(u_{n+1}-u_{n}\right)\right\| \\
& \quad=\left\|-\alpha_{n} x_{n}+\alpha_{n} T y_{n}+\beta_{n} x_{n}-\beta_{n} T x_{n}+\alpha_{n} u_{n}-\alpha_{n} T u_{n}\right\| \\
& \quad \leq \alpha_{n}\left(\left\|x_{n}\right\|+\left\|T y_{n}\right\|+\left\|u_{n}\right\|+\left\|T u_{n}\right\|\right)+\beta_{n}\left(\left\|x_{n}\right\|+\left\|T x_{n}\right\|\right) \\
& \quad \leq\left(\alpha_{n}+\beta_{n}\right) M \longrightarrow 0 \quad(n \rightarrow \infty),
\end{aligned}
$$

where

$$
M=\sup _{n}\left(\left(\left\|x_{n}\right\|+\left\|T y_{n}\right\|+\left\|u_{n}\right\|+\left\|T u_{n}\right\|\right),\left(\left\|x_{n}\right\|+\left\|T x_{n}\right\|\right)\right)<\infty .
$$

The sequences $\left(u_{n}\right)_{n},\left(x_{n}\right)_{n},\left(T x_{n}\right)_{n},\left(T u_{n}\right)_{n}$, and $\left(T y_{n}\right)_{n}$ are bounded being in the bounded set $B$. Hence one can see that the $M$ above is finite and (2.2) holds. We define

$$
\sigma_{n}:=2 \alpha_{n} M_{1}\left\|J\left(x_{n+1}-u_{n+1}\right)-J\left(y_{n}-u_{n}\right)\right\| .
$$


Again, using (1.1) and (1.3), we get

$$
\begin{aligned}
\left\|y_{n}-u_{n}\right\|^{2} & =\left\|\left(1-\beta_{n}\right)\left(x_{n}-u_{n}\right)+\beta_{n}\left(T x_{n}-u_{n}\right)\right\|^{2} \\
& \leq\left(1-\beta_{n}\right)^{2}\left\|x_{n}-u_{n}\right\|^{2}+2 \beta_{n}\left\langle T x_{n}-u_{n}, J\left(y_{n}-u_{n}\right)\right\rangle \\
& \leq\left\|x_{n}-u_{n}\right\|^{2}+\beta_{n} M_{2} .
\end{aligned}
$$

The last inequality is true because $\left(\left\langle T x_{n}-u_{n}, J\left(y_{n}-u_{n}\right)\right\rangle\right)_{n}$ is bounded, with a constant $M_{2}>0$. Replacing (2.5) and (2.6) in (2.1), we obtain

$$
\begin{aligned}
\left\|x_{n+1}-u_{n+1}\right\|^{2} \leq & \left(1-\alpha_{n}\right)^{2}\left\|x_{n}-u_{n}\right\|^{2}+2 \alpha_{n} k\left\|x_{n}-u_{n}\right\|^{2} \\
& +\sigma_{n}+\alpha_{n}(2 k) \beta_{n} M_{2} \\
= & \left(1-2(1-k) \alpha_{n}+\alpha_{n}^{2}\right)\left\|x_{n}-u_{n}\right\|^{2}+o\left(\alpha_{n}\right) .
\end{aligned}
$$

The condition $\lim _{n \rightarrow \infty} \alpha_{n}=0$ implies the existence of an $n_{0}$ such that, for all $n \geq n_{0}$, we have

$$
\alpha_{n} \leq(1-k)
$$

Substituting (2.8) into (2.7), we get

$$
1-2(1-k) \alpha_{n}+\alpha_{n}^{2} \leq 1-2(1-k) \alpha_{n}+(1-k) \alpha_{n}=1-(1-k) \alpha_{n} .
$$

Finally,

$$
\left\|x_{n+1}-u_{n+1}\right\|^{2} \leq\left(1-(1-k) \alpha_{n}\right)\left\|x_{n}-u_{n}\right\|^{2}+o\left(\alpha_{n}\right) .
$$

With $a_{n}:=\left\|x_{n}-u_{n}\right\|^{2}, \lambda_{n}:=(1-k) \alpha_{n} \in(0,1)$, and using Lemma 1.3, we obtain $\lim _{n \rightarrow \infty} a_{n}=\lim _{n \rightarrow \infty}\left\|x_{n}-u_{n}\right\|^{2}=0$, that is,

$$
\lim _{n \rightarrow \infty}\left\|x_{n}-u_{n}\right\|=0 \text {. }
$$

Let $x^{*}$ be the fixed point of $T$. Suppose that $\lim _{n \rightarrow \infty} u_{n}=x^{*}$. The inequality

$$
0 \leq\left\|x^{*}-x_{n}\right\| \leq\left\|u_{n}-x^{*}\right\|+\left\|x_{n}-u_{n}\right\|
$$

and (2.11) imply that $\lim _{n \rightarrow \infty} x_{n}=x^{*}$. Analogously, $\lim _{n \rightarrow \infty} x_{n}=x^{*}$ implies $\lim _{n \rightarrow \infty} u_{n}=x^{*}$.

REMARK 2.2. (i) If $T$ has a fixed point, then Theorem 2.1 holds without the continuity of $T$.

(ii) If $B$ is not bounded, then Theorem 2.1 holds, supposing that $\left(x_{n}\right)_{n}$ is bounded. The point was to prove that if Mann iteration is convergent (thus bounded), then Ishikawa iteration is convergent too. We remark that having the convergence of Ishikawa iteration, one can immediately deduce the convergence of Mann iteration by setting $\beta_{n}=0$ for all $n \in \mathbb{N}$ in (1.3). 
Theorem 2.1 does not completely generalize the Lipschitzian case from [10] because the operator there is not necessarily bounded.

THEOREM 2.3 [10]. Let $K$ be a closed convex (not necessary bounded) subset of an arbitrary Banach space $X$ and let $T$ be a Lipschitzian pseudocontractive selfmap of $K$. We consider Mann iteration and Ishikawa iteration with the same initial point and with the conditions $\lim _{n \rightarrow \infty} \alpha_{n}=0, \lim _{n \rightarrow \infty} \beta_{n}=0$, and $\sum_{n=1}^{\infty} \alpha_{n}=\infty$. Let $x^{*} \in F(T)$. Then the following conditions are equivalent:

(i) Mann iteration (1.1) converges to $x^{*} \in F(T)$;

(ii) Ishikawa iteration (1.3) converges to $x^{*} \in F(T)$.

3. Further equivalences. Let $S$ be a strongly accretive operator. We consider when the equation $S x=f$ has a solution for a given $f \in X$. It easy to see that

$$
T x=x+f-S x, \quad \forall x \in X,
$$

is a strongly pseudocontractive operator. A fixed point for $T$ is the solution of $S x=f$, and conversely. Theorem 2.1 assures that the convergence of Mann and Ishikawa iterations to the fixed point of $T$ are equivalent for bounded strongly pseudocontractive maps. A similar result holds for the convergence of Mann and Ishikawa iterations to the solution of $S x=f$. Suppose that the operator $S$ is strongly accretive. It is well known that if $S$ is bounded, $(I-S)$ could be unbounded. Take, for example, $S: R \rightarrow B=[-1,1]$ with $S(x)=(1 / 2) \cos x$. According to [2], the map $(I-S)(x)=x-(1 / 2) \cos x$ is strongly accretive and $(I-S)(R)=R$. Thus, if $B$ is bounded and $x \in B$ does not mean that $T x=x-S x+f \in B$. For the same $\left(\alpha_{n}\right)_{n},\left(\beta_{n}\right)_{n} \subset(0,1)$ as in (1.4), iterations (1.1) and (1.3) become

$$
\begin{aligned}
x_{n+1} & =\left(1-\alpha_{n}\right) x_{n}+\alpha_{n}\left(f+(I-S) y_{n}\right), \\
y_{n} & =\left(1-\beta_{n}\right) x_{n}+\beta_{n}\left(f+(I-S) x_{n}\right), \quad n=1,2, \ldots, \\
u_{n+1} & =\left(1-\alpha_{n}\right) u_{n}+\alpha_{n}\left(f+(I-S) u_{n}\right), \quad n=1,2, \ldots .
\end{aligned}
$$

The existence of the solution for $S x=f$ when $S$ is a continuous and strongly accretive operator results from [8]. This argument and Remark 2.2(ii) lead us to the following corollary.

COROLLARY 3.1. Let $X$ be a real Banach space with a uniformly convex dual and $B$ a nonempty, convex, and closed subset of $X$. Let $S: B \rightarrow B$ be a continuous and strongly accretive operator and let $\left(x_{n}\right)_{n}$, given by (3.2), be bounded. Then, for $u_{1}=x_{1} \in B$, the following assertions are equivalent:

(a) Mann iteration (3.3) converges to the solution of $S x=f$;

(b) Ishikawa iteration (3.2) converges to the solution of $S x=f$. 
Let $S$ be an accretive operator. From Remark 1.2(ii), the operator $T x=f-S x$ is strongly pseudocontractive for a given $f \in X$. A solution for $T x=x$ becomes a solution for $x+S x=f$. For $\left(\alpha_{n}\right)_{n},\left(\beta_{n}\right)_{n} \subset(0,1)$, as in (1.4), iterations (1.1) and (1.3) become

$$
\begin{aligned}
x_{n+1} & =\left(1-\alpha_{n}\right) x_{n}+\alpha_{n}\left(f-S y_{n}\right), \\
y_{n} & =\left(1-\beta_{n}\right) x_{n}+\beta_{n}\left(f-S x_{n}\right), \quad n=1,2, \ldots, \\
u_{n+1} & =\left(1-\alpha_{n}\right) u_{n}+\alpha_{n}\left(f-S u_{n}\right), \quad n=1,2, \ldots .
\end{aligned}
$$

The existence of a solution for this equation follows from [7]. We are now able to give the following result.

COROLLARY 3.2. Let $X$ be a real Banach space with a uniformly convex dual and $B$ a nonempty, convex, and closed subset of $X$. Let $S: B \rightarrow B$ be a continuous and accretive operator and let $\left(x_{n}\right)_{n}$, given by (3.4), be bounded. Then, for $u_{1}=x_{1} \in B$, the following assertions are equivalent:

(a) Mann iteration (3.5) converges to the solution of $x+S x=f$;

(b) Ishikawa iteration (3.4) converges to the solution of $x+S x=f$.

Observe that if $S$ is not continuous, and the equations $S x=f$, respectively, $x+S x=f$, have solutions, then Corollary 3.1, respectively, Corollary 3.2 hold.

We remark that all the results from this paper hold in the multivalued case, provided that these multivalued maps admit appropriate single-valued selections.

\section{REFERENCES}

[1] S.-S. Chang, On Chidume's open questions and approximate solutions of multivalued strongly accretive mapping equations in Banach spaces, J. Math. Anal. Appl. 216 (1997), no. 1, 94-111.

[2] C. E. Chidume and M. O. Osilike, Iterative solutions of nonlinear accretive operator equations in arbitrary Banach spaces, Nonlinear Anal. 36 (1999), no. 7, Ser. A: Theory Methods, 863-872.

[3] K. Deimling, Zeros of accretive operators, Manuscripta Math. 13 (1974), 365-374.

[4]_, Nonlinear Functional Analysis, Springer-Verlag, Berlin, 1985.

[5] S. Ishikawa, Fixed points by a new iteration method, Proc. Amer. Math. Soc. 44 (1974), 147-150.

[6] W. R. Mann, Mean value methods in iteration, Proc. Amer. Math. Soc. 4 (1953), 506-510.

[7] R. H. Martin Jr., A global existence theorem for autonomous differential equations in a Banach space, Proc. Amer. Math. Soc. 26 (1970), 307-314.

[8] C. H. Morales, Surjectivity theorems for multivalued mappings of accretive type, Comment. Math. Univ. Carolin. 26 (1985), no. 2, 397-413.

[9] C. H. Morales and J. S. Jung, Convergence of paths for pseudocontractive mappings in Banach spaces, Proc. Amer. Math. Soc. 128 (2000), no. 11, 34113419.

[10] B. E. Rhoades and S. M. Soltuz, On the equivalence of Mann and Ishikawa iteration methods, Int. J. Math. Math. Sci. 2003 (2003), no. 7, 451-459. 
[11] X. Weng, Fixed point iteration for local strictly pseudocontractive mapping, Proc. Amer. Math. Soc. 113 (1991), no. 3, 727-731.

B. E. Rhoades: Department of Mathematics, Indiana University, Bloomington, IN 47405-7106, USA

E-mail address: rhoades@indiana.edu

Ştefan M. Şoltuz: “T. Popoviciu” Institute of Numerical Analysis, P.O. Box 68-1, 3400 Cluj-Napoca, Romania

E-mail address: stefanso1tuz@persona1 .ro 


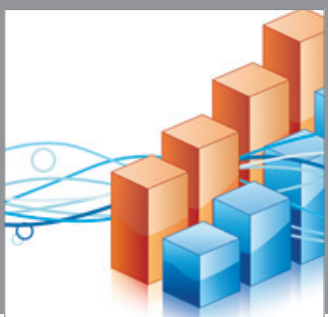

Advances in

Operations Research

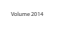

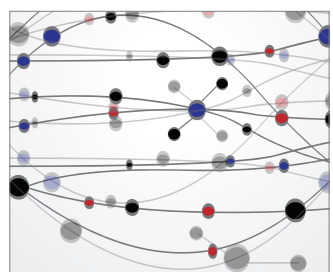

\section{The Scientific} World Journal
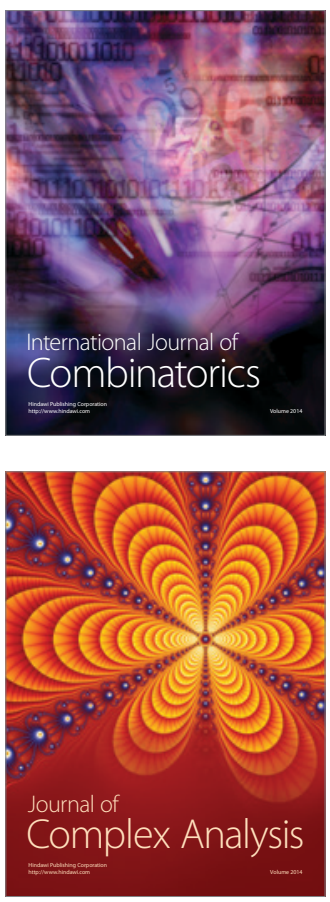

International Journal of

Mathematics and

Mathematical

Sciences
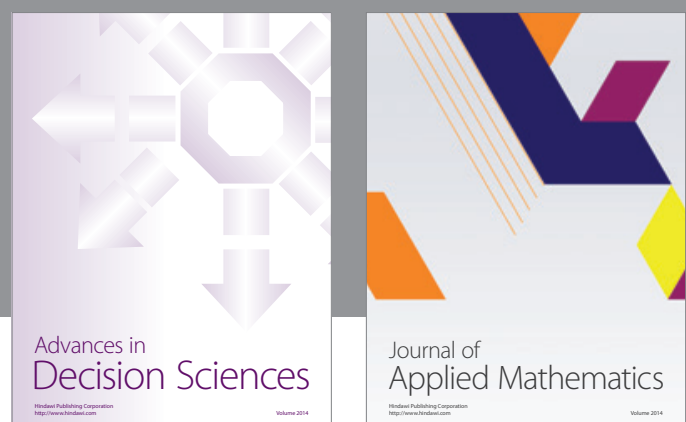

Journal of

Applied Mathematics
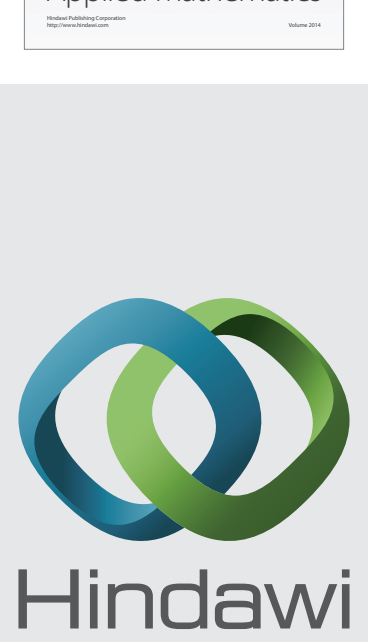

Submit your manuscripts at http://www.hindawi.com
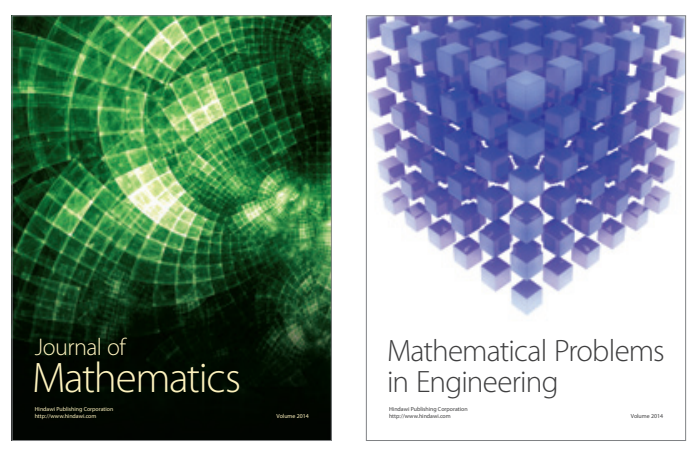

Mathematical Problems in Engineering
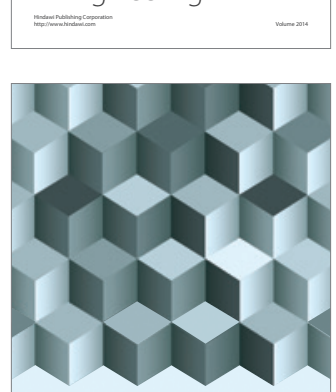

Journal of

Function Spaces
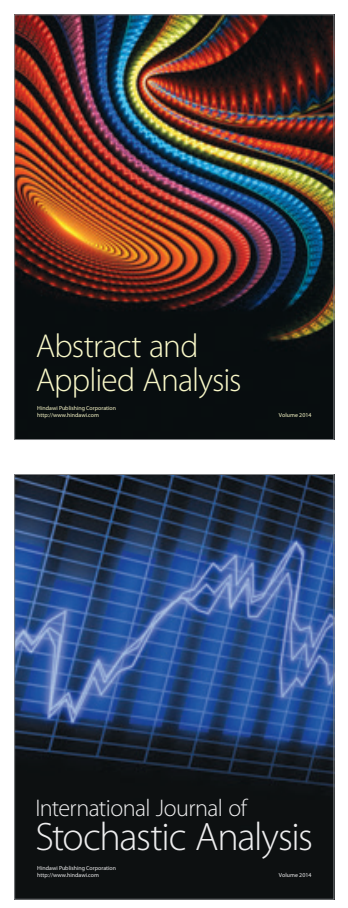

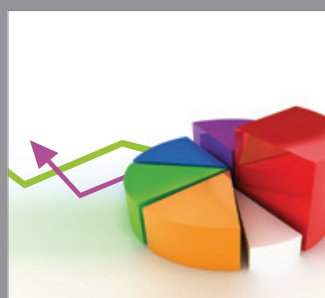

ournal of

Probability and Statistics

Promensencen
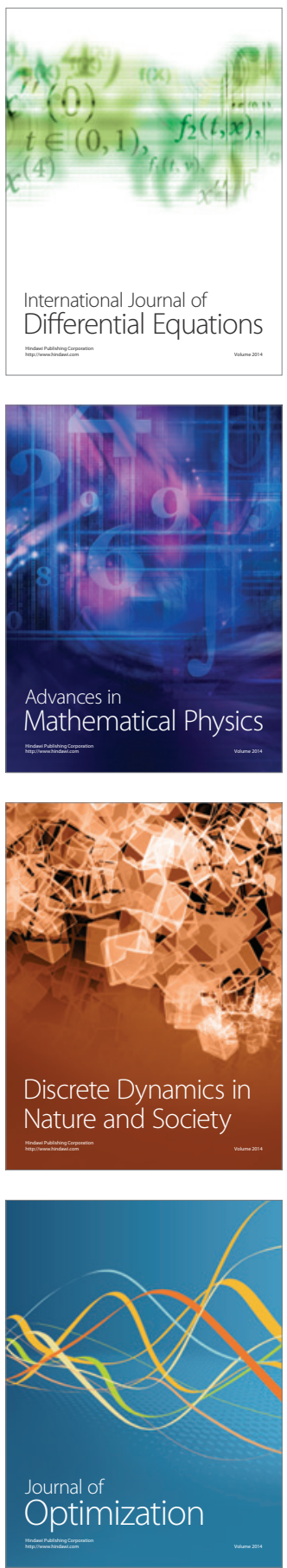